\title{
Smouldering natural fires: comparison of burning dynamics in boreal peat and Mediterranean humus
}

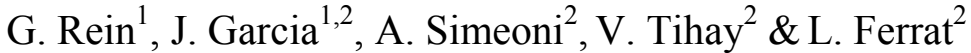 \\ ${ }^{1}$ BRE Centre for Fire Safety Engineering, University of Edinburgh, UK \\ ${ }^{2}$ UMR CNRS 6134 - SPE, Università di Corsica, France
}

\begin{abstract}
Smouldering of the forest subsurface can be responsible for a large fraction of the total fuel consumed during wildfires. Subsurface fires can take place in organic material stored in shallow forest layers such as duff or humus, and in deeper layers such as peat, landfills and coal seams. These fires play a major role in the global emission to the atmosphere, the destruction of carbon storage in the soil and the damage to the natural environment. Burning dynamics in two different ecosystems affected by smouldering wildfires are studied here; boreal peat and Mediterranean humus. A series of small-scale smouldering experiments have been conducted under laboratory conditions to study the ignition and the severity to the soil. The experimental set-up allowed the temperature and velocity of the fire front to be measured for different fuel moisture contents. The two fuels, peat and humus, were tested and the results are compared.
\end{abstract}

Keywords: subsurface, wildfire, organic soil, duff, smoulder.

\section{Introduction}

When a layer of organic soil ignites, it burns steadily without flames and propagates slowly into the soil. Large smouldering fires are rare events at the local scale but occur regularly at the global scale. Once ignited, they are particularly difficult to extinguish despite extensive rains or firefighting attempts and can linger for long periods of time (weeks and up to years; Page et al. [1]; Svensen et al. [2]), and spread over very extensive areas of forest and deep into the soil. By propagating below the surface, smouldering fires offer the means for 
flaming combustion to re-establish during wildfires in unexpected locations (e.g. across a fire break) and at unexpected times (e.g. long after burn out of the flame front). These fires represent a large contributor to biomass consumption and a significant source of combustion emissions to the atmosphere (Page et al. [1], Bertschi et al. [3]).

Smouldering of the forest subsurface can be responsible for a large fraction of the total fuel consumed during wildfires. Subsurface fires can take place in organic material stored in shallow forest layers such as duff or humus, and in deeper layers such as peat and coal seams. These fires play a mayor role in the global emission to the atmosphere, the destruction of carbon storage in the soil and the damage to the natural environment. The two fuels, peat and humus, were tested and the results are compared in this paper.

Of all the natural organic soils, fire in peatlands is the most common and has been reported in tropical, temperate and boreal forests. Peat is partially decayed vegetation matter, which has accumulated and decomposed in wetlands. It can have very high moisture contents (several times the weight of the organic content), and forms layers of depths ranging from a few centimetres to dozens of meters. Of all the peat lands in the world, about $80 \%$ are situated in northern temperate regions, $15-20 \%$ in tropical or subtropical regions and only a few are in southern temperate regions. Peatlands cover over $410^{6} \mathrm{~km}^{2}(3 \%$ of the Earth's land surface) and are important ecosystems for a wide range of wildlife habitats supporting biological diversity, hydrological integrity and carbon storage. These ecosystems hold one third of the world's soil carbon and $10 \%$ of global freshwater resources. Their total carbon pool exceeds that of the world's forests and is comparable to that of the atmosphere.

In every terrestrial ecosystem organic litter is accumulated to a certain degree making humus forms. Its intermediate position in space and time between living organisms and dead mineral compounds makes a humus form the centre of regulation of the soil and, some extent, of the whole ecosystem. Humus results from the biochemical transformation of residual vegetation by decomposer foodwebs, including readily decomposable materials, plant litter and roots, and dead and living organisms. Humic substances make up a significant portion of the total organic carbon and nitrogen in soil. They consist of complex polymeric organic compounds, which are more resistant to decomposition than the nonhumic material (Masciandaro and Ceccanti [4]). The composition of humus depends on the nature of the vegetal cover. It is usually composed of 3 fractions (Heller et al. [5]):

- Humic acids sensu stricto, of black or brown colour, composed of lignoproteic complexes, are the most abundant, Fulvic acids, of brown-red colour, are essentially composed of hemicellulose derivates and waxes,

- The neutral or basic fraction, called humine, composed of cellulose fragments.

- The organic layers over the mineral soil (litter and humus) present in most forest soils play a vital role within the forest ecosystem, increasing the soil aggregation and the rate of infiltration. (Pikul and Zuzel [6]). 


\section{Smouldering fires}

Smouldering is the flameless form of combustion of a solid fuel (Palmer [7], Drysdale [8]). The fundamental difference between smouldering and flaming combustion is that, in the former, the oxidation reaction and the heat release occur on the surface of the solid and, in the latter, these occur in the gas phase above the fuel. Figure 1 shows a snapshot of the two burning regimes in forest floor biomass.

The characteristic temperature, spread rate and heat release rate during smouldering are low compared to those in the flaming combustion. Typical values for smouldering of biomass are $500-700{ }^{\circ} \mathrm{C}$ for the peak temperature and $1-50 \mathrm{~mm} / \mathrm{h}$ for the spread rate; whereas typical values for flaming are around $1500{ }^{\circ} \mathrm{C}$ and $1000 \mathrm{~mm} / \mathrm{h}$ respectively (Drysdale [8]). The hazards associated with smouldering arise because it can be initiated by weak sources of heat; yields a high conversion of biomass to volatile organic compounds, carbon monoxide and polyaromatic hydrocarbons (Bertschi et al. [3]); is difficult to detect and extinguish; and it can abruptly transition to flaming combustion.

Biomass fuels prone to smouldering include stumps, snags, downed logs, large branches, roots, duff, peat, coal and other organic soils. These fuels generally consist of an aggregate medium formed by particulates, grains, fibres or a porous matrix. The aggregate contains the organic fraction that burns during the fire. These fuels are characterized by having a significantly greater characteristic thermal time than fine fuels but allow oxygen transport to the surface; characteristics that lead to the slow but persistent burning typical of smouldering combustion.

\section{Small-scale experiments}

The only systematic experiments of peat ignition are those by Frandsen [9, 10]. These were pioneering work to investigate the relationship between the moisture content and smouldering behaviour. These report on an experimental apparatus that allow measuring the critical moisture content above which ignition is not possible. An experimental apparatus similar to that of Frandsen [9] has been built for this work. Modifications have been made to measure spread and temperature evolution and distribution. This apparatus provides a simple procedure to capture the essentials of peat ignition and propagation. It allows estimation of the moisture content below which ignition is highly probable (the critical moisture) and characterization of the thermal severity of smouldering.

Figure 1 shows the experimental set up and the progression of the smouldering front during one experiment. The tests were conducted in a small box $100 \times 100 \times 100 \mathrm{~mm}$ made of insulating board and open at the top. Samples are of dimensions $100 \times 100 \mathrm{~mm}$ across and $50 \mathrm{~mm}$ in depth. Ignition is attempted using an electrically heated coil running along one side of the sample. The coil is a spiral $10 \mathrm{~mm}$ diameter and $95 \mathrm{~mm}$ long. It was buried in the fuel at a depth of $30 \mathrm{~mm}$ and placed next to the left wall of the experimental apparatus (see Fig. 1). The ignition protocol consisted of supplying the coil with a power of 
$100 \mathrm{~W}$ during $30 \mathrm{~min}$. In order to reduce the sensitivity of the results to the details of the ignition protocol, a vigorous ignition roughly equivalent to the heating from a flaming stump is chosen. The criterion for ignition rating is based on the propagation of the smouldering front away from the igniter and through the full sample. This ignition protocol and criterion are used because the measured critical moisture in small-scale samples could, to some extent, be sensitive to the ignition protocol. This protocol and criterion provide the upper bound of the critical moisture and is valid for conservative ignition ratings.

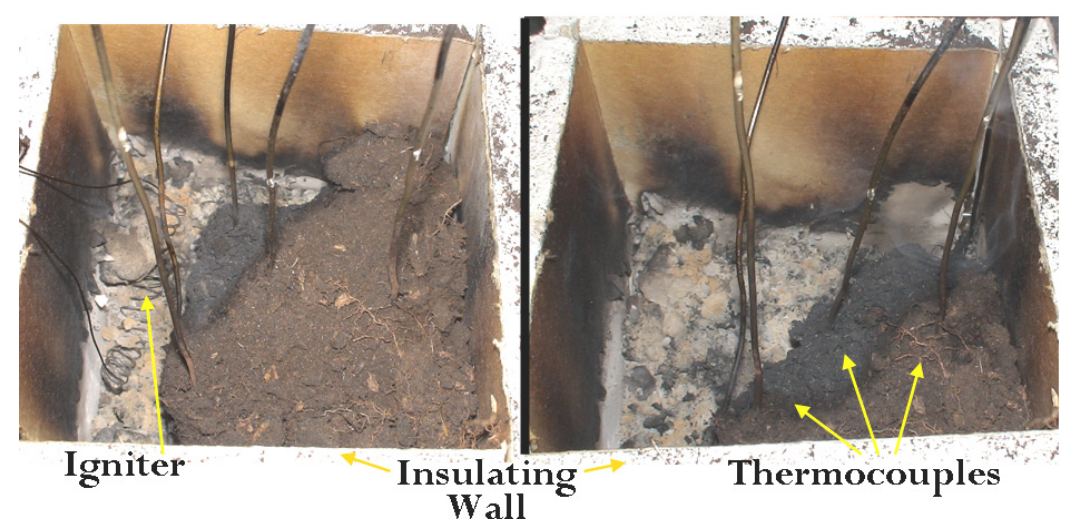

Figure 1: Snapshots during a peat experiment.

Five thermocouples are placed within the sample to a depth of $40 \mathrm{~mm}$. One thermocouple is placed near the igniter coil, less than $10 \mathrm{~mm}$ from the left wall; two thermocouples are placed along the central axis to register the longitudinal propagation (at the sample centre $50 \mathrm{~mm}$ from the left wall, and at the sample end $10 \mathrm{~mm}$ from the right wall); and one thermocouple is placed on either side of the sample to register the lateral propagation $(10 \mathrm{~mm}$ from side walls and $30 \mathrm{~mm}$ from the igniter).

\section{Fuel}

\subsection{Peat}

Peatlands are regularly subject to fires under dry conditions. Peat fires affect the structural stability of the ground and heat the soil, damaging plant roots and sterilizing the soil. At a global scale, they contribute significantly to the emission of carbon dioxide to the atmosphere. See Rein et al. [15] for a more complete description of peat fires.

Boreal peat was collected from a site south of Edinburgh, Scotland. The samples were cut from several blocks of old, moderately decomposed herbaceous peat. The measured bulk density of the dry mass was $130 \mathrm{~kg} \cdot \mathrm{m}^{-3}$ and the mineral content was $8 \pm 2 \%$ in dry base (measured as the mass fraction left after complete combustion with a flame torch). The moisture content of the peat 
samples was varied between $85 \%$ and $160 \%$ by placing samples of approximate initial moisture $400 \%$ in an oven at $80{ }^{\circ} \mathrm{C}$ for varying periods of time. The moisture within the sample was allowed to equilibrate by placing it during 3 days at ambient temperature and wrapped in plastic.

\subsection{Humus}

Because fire is expected to trigger erosion (Wright and Heinselman [11]) or to control the tree recruitment when humus is consumed (Greene et al. [12]). Erosion resulting from fire is due to a total destruction of litter and humus layers by severe surface fires. Low severity surface fires do not cause erosion because the litter layer survives and protects the soil. However, it is classically assumed that erosion is strongly stimulated by fires (Meyer et al. [13]).

Lightning can be a source of fire ignition when moisture content of fine fuels is very low (Rorig and Ferguson [14]). In winter, they consist in a slow fire that propagates on the ground and sometimes under it. These fires can emerge from the ground following roots, snags or dropped logs. Fire-fighters usually make trenches to suppress the fuel on the ground and to avoid propagation. They can also treat the hot spots with water. In summer, these fires are not usually encountered, but the presence of hot spots after a fire like a smouldering stump is frequent.

The main forecasts for the climate change in the Mediterranean region, expect an increase of very dry and hot summer occurrence. Under these very dry conditions, smouldering can become very hard to extinguish. As an example, 2003 was a very dry and hot summer in Corsica (but also in the whole Mediterranean region) and fires were very difficult to extinguish. These fires can move to flaming forest fires if appropriate conditions are reached (dryness, continuity in vegetation and wind among others). Indeed, these fires can emerge from the ground following roots, snags or dropped logs. The more the fire lasts, the more the risk to have transition. This situation was encountered in 2003 in North Corsica, when a smouldering fire remaining 10 days and moved suddenly to a big forest fire because of high winds, destroying 16 houses, killing 1 people and injured several others.

The measured bulk density of the dry mass was $160 \mathrm{~kg} \cdot \mathrm{m}^{-3}$ and the mineral content was $11 \pm 2 \%$ in dry base (measured as the mass fraction left after complete combustion with a flame torch). Collection of samples has taken place in the central area of Corsica under Pinus Pinaster groves, characteristic of Mediterranean forests. Humus found in the field had moisture contents from $170-210 \%$ (dry basis). Following the protocol with peat, the samples where tested under laboratory conditions. An oven was used to reduce the moisture content to $75-180 \%$ (dry basis).

\section{Results}

The measured mass loss vs. moisture content for all the tests is presented in Figure 2 for the two fuels. The results in for peat Fig. 2.a show the sharp transition separating low and large mass losses at the critical moisture of 
$125 \pm 10 \%$. This value compares well to the work by Frandsen [9] whose experiments showed that the critical moisture for peat moss is $105 \%$ for a mineral content of $8 \%$ in dry mass (the content of peat in our experiments). For humus, the critical moisture value is the same (125 $\pm 5 \%$ in Fig. 2.b), showing a similar behaviour between the two fuels. This result is surprising considering the different nature of the two fuels and demonstrates a common influence of moisture in smouldering fronts through shallow biomass layers.

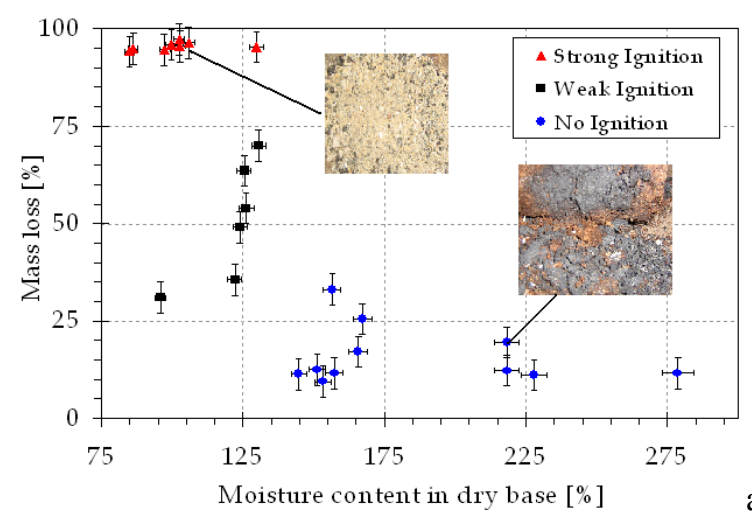

a)

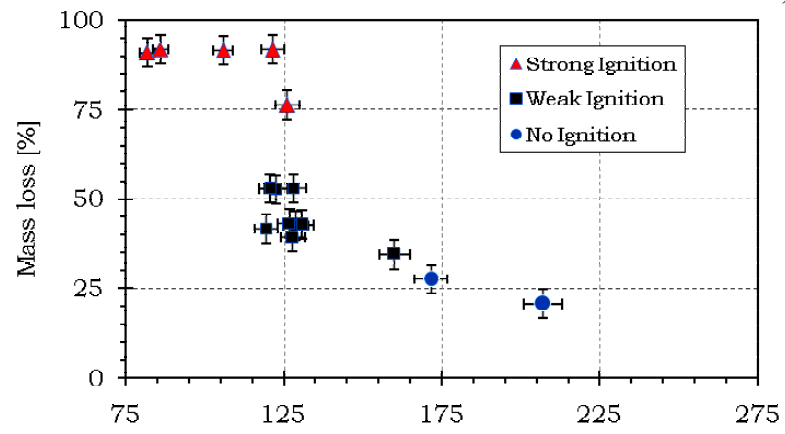

Moisture content dry base [\%]

b)

Figure 2: $\quad$ Results for total mass lost in the sample vs. moisture content for a) boreal peat $b$ ) humus.

As shown in Figs. 2, the spreading, critical and no-spreading conditions were classified as strong, weak and no ignition (see Rein et al. [15]).

Figures 3 show successful ignitions followed by sustained smouldering fronts. These ignitions resulted in a maximum temperature at the fuel in contact with the coil over $600{ }^{\circ} \mathrm{C}$. Fig. 3.a, the thermocouple located at the centre of the box displays a typical smouldering peak temperature around $550{ }^{\circ} \mathrm{C}$. The front consumed the sample in $3.7 \mathrm{~h}$. Humus displayed less intense smouldering fronts with a peak temperature of around $480{ }^{\circ} \mathrm{C}$ (see Fig. 3.b) and the front consumed the sample in $4.9 \mathrm{~h}$. The mean front velocities were $3 \mathrm{~cm} / \mathrm{h}$ and $2 \mathrm{~cm} / \mathrm{h}$, for peat and humus, respectively. 


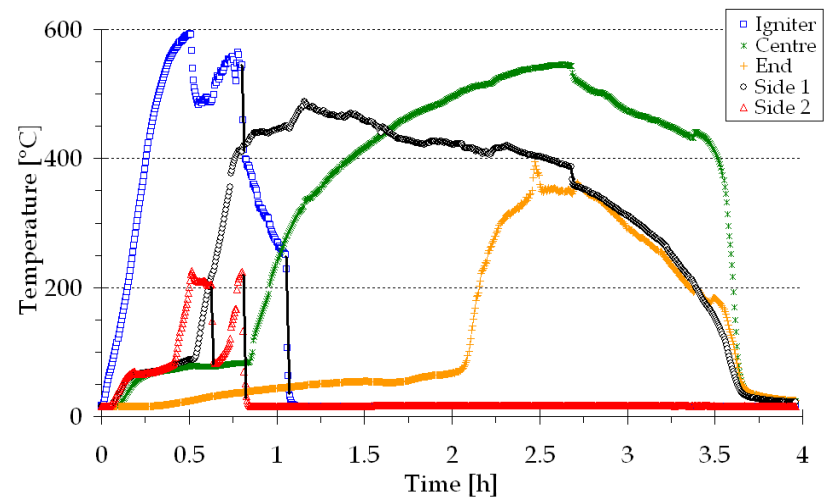

a)

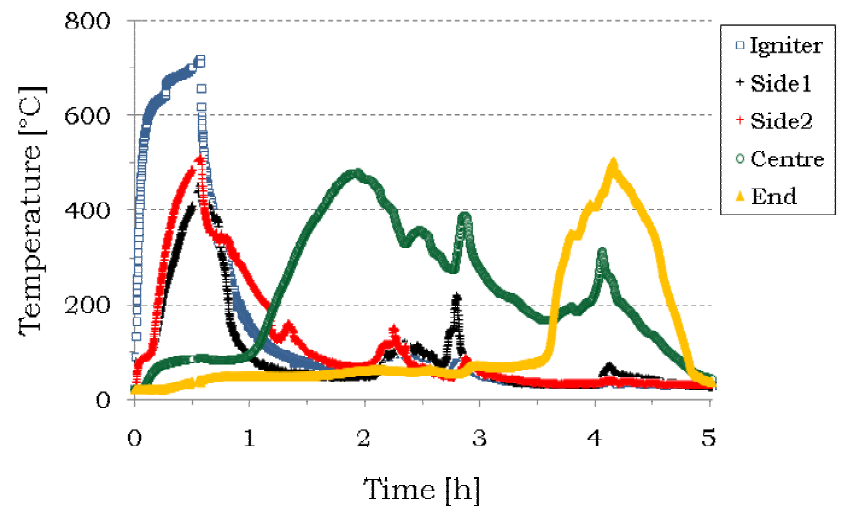

b)

Figure 3: Temperature readings from samples that underwent strong ignition and propagation for $a$ ) peat $b$ ) humus.

The experimental results can be used to quantify fire severity (Rein et al. [15]). The thermocouple readings provide the history of the severity in terms of temperature and residence-time, and the mass loss measurements quantify the soil removal.

The peak temperatures observed away from the igniter for sample that burned completely (moisture below the critical) was between 450 and $600{ }^{\circ} \mathrm{C}$ for many min, enough to produce severe and irreversible alteration to the affected soil and its sterilization. But more information can be gained from the thermocouple readings and the fire severity has been quantified in terms of the time that a location is held over a given temperature.

Figures 4 display the mean temperatures vs. residence times. Side bars indicate standard deviation. We used the records at the middle of the sample as the results were not influenced by the igniter and the boundaries of the box. Large differences can be seen between the residence times recorded in the regions near and away from the igniter. On average, no-ignition samples barely go above $500{ }^{\circ} \mathrm{C}$ near the igniter and do not go above $200{ }^{\circ} \mathrm{C}$ away from igniter. 


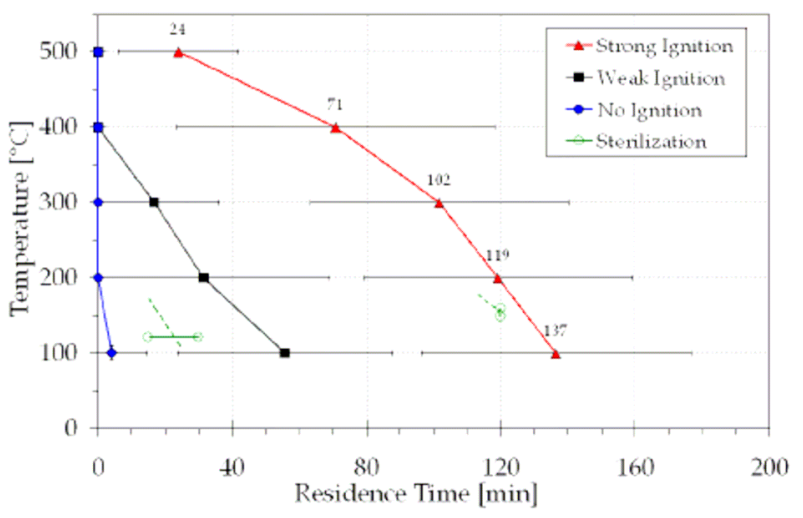

a)

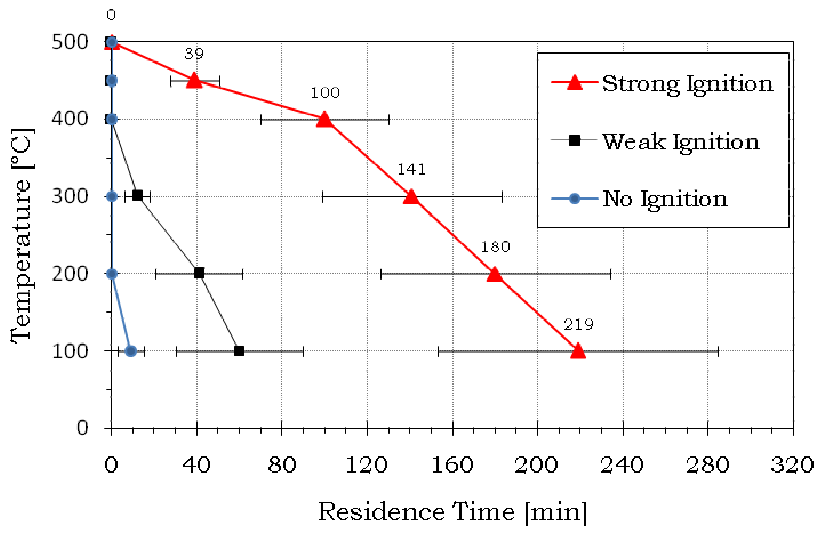

b)

Figure 4: Thermal fire severity for the three different ignition regimes a) peat b) humus.

When looking at weak-ignition samples, some difference between the two regions can be seen, but near the igniter, fire severity is considerably higher (more than twice the resident times) than away from it. The results for the strong ignition are almost identical in both locations, indicating that the event is independent of the external ignition and that the thermal severity for smouldering fires would be well characterized by these results.

The residence times for humus are greater than the ones for peat as the smouldering front is less intense. Nevertheless, the temperatures are high enough with residence times long enough to sterilize soils (Block [16]).

\section{Conclusions}

A series of smouldering experiments of boreal peat and Mediterranean humus have been conducted under laboratory conditions. Samples of different moisture 
contents were exposed to an external ignition source while temperature evolution in the bed and final mass loss were measured.

The measured critical moisture content for this boreal peat is found to be $125 \pm 10 \%$ for peat and $125 \pm 5 \%$ in humus. The similitude of the results for both fuels is remarkable.

The common critical behaviour is independent of the intensity of the smouldering front as humus exhibits less intense fronts than peat (lower rate of spread and temperature). These differences could be due to the different nature of the fuel, but also to a difference in porosity.

The results can allow the development of a simple and conservative fire danger rating that could be used by forest managers and fire services in soil with mineral content around $11 \%$ in dry base. If field moisture measurements indicate that the water content in shallow peat layers is below $115 \%$ in dry base, then the fire danger would be high, if between $115 \%$ and $135 \%$ the danger would be intermediate, and for moistures above $135 \%$ the fire danger would be low.

The study of smouldering fires and the response of the ecosystem will become even more important if, as climate experts predict, warmer and drier summers are to be expected in the future bringing an increased wildfire frequency.

\section{Acknowledgements}

This research has been partially funded by the Met Office, Natural England and British Council-French Foreign Affairs Ministry Alliance Programme. The collaboration and help from JL. Torero, N. Cleaver, C. Ashton, M. Davies, C. Legg, R. Hadden, V. Pasqualini and F. Morandini is appreciated.

\section{References}

[1] Page, S.E., Siegert, F., Rieley, J.O., Boehm, H.D.V., Jaya, A., Limin, S., 2002. The amount of carbon released from peat and forest fires in Indonesia during 1997. Nature 420, 61-63.

[2] Svensen, H., Dysthe, DK., Bandlien, EH., Sacko, S., Coulibaly, H., Planke, S., 2003. Subsurface combustion in Mali: Refutation of the active volcanism hypothesis in West Africa. Geology 31, 581-584.

[3] I. Bertschi, RJ Yokelson, DE Ward, RE Babbitt RA Susott, JG Goode, WMJ Hao, Geophysical Research 108 (2003), 8472.

[4] Masciandaro G., Ceccanti B., 1999. Assessing soil quality in different agroecosystems through biochemical and chemico-structural properties of humic substances. Soil and Tillage Research, 51(1-2): 129-137.

[5] Heller, R., Esnault R., Lance C., 1998. Physiologie végétale: Nutrition. Dunod Ed. 323p.

[6] Pikul, J.L., Zuzel, J.F., 1994. Soil crusting and water infiltration affected by long-term tillage and residue management. Soil Science Society of America Journal 58, 1524- 1530 . 
[7] Palmer, K.N., 1957. Smoldering combustion in dusts and fibrous materials. Combustion and Flame 1, 129-154.

[8] Drysdale, D., 2004. An Introduction to Fire Dynamics, 2nd Ed, John Wiley \& Sons.

[9] Frandsen, W.H., 1987. The influence of moisture and mineral soil on the combustion limits of smouldering forest duff. Canadian Journal of Forest Research 17 (12), 1540-1544.

[10] Frandsen, W.H., 1997. Ignition probability of organic soils. Canadian Journal of Forest Research 27, 1471-1477.

[11] Wright Jr, H.E., Heinselman, M.L., 1973. Introduction. Quaternary Research 3, 319-328.

[12] Greene, D.F., Noe 1, J., Bergeron, Y., Rousseau, M., Gauthier, S., 2004. Recruitment of Picea mariana, Pinus banksiana, and Populus tremuloides across a burn severity gradient following wildfire in the southern boreal forest of Quebec. Canadian Journal of Forest Research 34, 1845-1857.

[13] Meyer, V.F., Redente, E.F., Barbarick, K.A., Brobst, R.B., Paschke, M.W., Miller, A.L., 2004. Plant and soil responses to biosolids application following forest fire. Journal of Environmental Quality 33, 873-881.

[14] Rorig, M.L., Ferguson, S.A., 1999. Characteristics of lightning and wildland fire ignition in the Pacific Northwest. J. Appl. Meteorol. 38, 1565-1575.

[15] Rein, G., Cleaver, N., Ashton, C., Pironi P., Torero JL., 2008. Fire Severity from Smouldering Peat to the forest Soil. Catena (in press).

[16] Block, S.S., 2001. Disinfection, Sterilization, and Preservation, Lippincott Williams \& Wilkins. 